\title{
Project and Analysis of Quasi-Periodic PBG for Microstrip Antenna
}

\author{
Ádller O. Guimarães ${ }^{1} \mathbb{D}$, Tarcisio S. Barreto ${ }^{2} \mathbb{D}$, José P. Silva $^{2} \mathbb{C}^{\mathbb{D}}$, Francisco C. B. de Sena ${ }^{1} \mathbb{D}$, \\ Jonathan P. P. Pinheiro ${ }^{3}$ (D), Otávio P. Lavor ${ }^{1}$ (D) \\ ${ }^{1}$ Federal Rural University of Semiarid, adller.guimaraes@ufersa.edu.br, chagassenal @gmail.com, \\ otavioplavor@gmail.com \\ ${ }^{2}$ Federal University of Rio Grande do Norte, tarcisiofip2@gmail.com, patroc.silva@gmail.com \\ ${ }^{3}$ Federal Institute of Education, Science and Technology of Rio Grande do Norte, \\ jonathan.pereira@ifrn.edu.br
}

\begin{abstract}
In this work the influence of quasi-periodic distributions of air holes with 6, 12 and 6-fold modified symmetries, applied to the substrate of a rectangular microstrip patch antenna are analyzed. To validate the study, parameters such as $S_{11}$ parameter, bandwidth, total gain, radiation pattern and electric field were investigated through computational simulations. The results obtained for all the PBG structures were compared to each other and to a reference antenna without PBG. In addition, we analyzed the resonating modes of each structure and it was observed improvements in bandwidth and gain for all modified structures when compared with the reference antenna, as well as reduction of the dielectric constant that is also recalculated. Some prototypes were built to compare the computational results to the measured results. It was verified that the measured and simulated results of return loss are in agreement and the antenna with 6-fold modified symmetry presented better performance than the others analyzed PBG structures.
\end{abstract}

Index Terms - Microstrip Antenna, PBG, Quasi-periodic distributions.

\section{INTRODUCTION}

Due to the advancement of technologies in modern communication systems, which require the construction of sophisticated microwave integrated circuits, currently there is a need for reduced size and good performance devices. In this context, planar microstrip antennas have been used in many different systems, such as space aircraft, satellites, airplanes and mobile communication systems [1][3].

However, this type of antenna also presents some drawbacks that can compromise its usage, for instance, low efficiency, low directivity and narrow bandwidth [4]-[8]. Because of that, new types of antennas have been developed by using prohibited bands in the substrate for which the propagation of electromagnetic waves at a certain frequency bands suffer strong attenuation, allowing an increasement in the bandwidth and radiation periodicity of the device, but without increasing the dimensions of the antenna [9]-[14]. Such structure is known as photonic band gap or just PBG structures. 
A photonic crystal is a structured material such that its dielectric constant varies periodically in space and it can be considered, depending on the application, as periodic nanostructures. Also, it is designed to affect the motion of photons in a similar manner that the periodicity of a semiconductor crystal affects the movement of electrons [15]-[17]. On the other hand, photonic quasi-crystals (PQC) are structurally different and it exhibits divergent behaviour of the photonic crystals. They are characterized by a very unusual alignment of the atoms and contain aperiodic structures, i.e., which have at least two different symmetrical patterns, also forming a structure without gaps, but not repeated regularly. Thus, due to these circumstances, it can cause symmetry $6,8,10$ and 12-fold, based on the number of repetitions of the standard PQC cell [18]-[20].

In this paper, three quasi-periodic settings for PBG mesh with 6, 12 and 6-fold modified symmetries were printed in the substrate of a standard rectangular microstrip antenna and the radiations properties were analyzed. Also, the antennas were fed by using a microstrip line and to match the impedances we have used inset cut in the patch. The dimensions of the antennas were designed to operate in the fundamental mode $\left(\mathrm{TM}_{10}\right)$ at $5.8 \mathrm{GHz}$. Simulation software was used to analyze the performance of the proposed antennas and the computational results were compared to those one obtained through measurements of three prototypes.

The next section presents the project for the reference antenna and proposed quasi-periodic PBG structures. In section III, computational results are showed. Experimental results, obtained from the construction of the proposed antennas, are described in section IV. Finally, conclusions are showed in section V.

\section{DESIGN OF QUASI-PERIODIC PBG ANTENNAS}

To compare the results provide by the proposed PBG structure was designed a standard rectangular patch antenna which was used as reference antenna, being fed by microstrip line with input impedance of $50 \Omega$. That antenna is supposed to resonate at $5.8 \mathrm{GHz}$, as described in [21]-[22]. As a result, we obtained a width $(W)$ of $15.73 \mathrm{~mm}$ and length $(L)$ of $11.74 \mathrm{~mm}$ for the patch. To the inset cut in the patch, we obtained $(g)$ of $0.86 \mathrm{~mm}$ and length $\left(y_{0}\right)$. The dimensions of the microstrip line were $3.28 \mathrm{~mm}$ and $6.59 \mathrm{~mm}$ for width and length, respectively. The material used for the patch, ground plane and microstrip line was copper with $0.05 \mathrm{~mm}$ of thickness, as showed in Fig. 1.
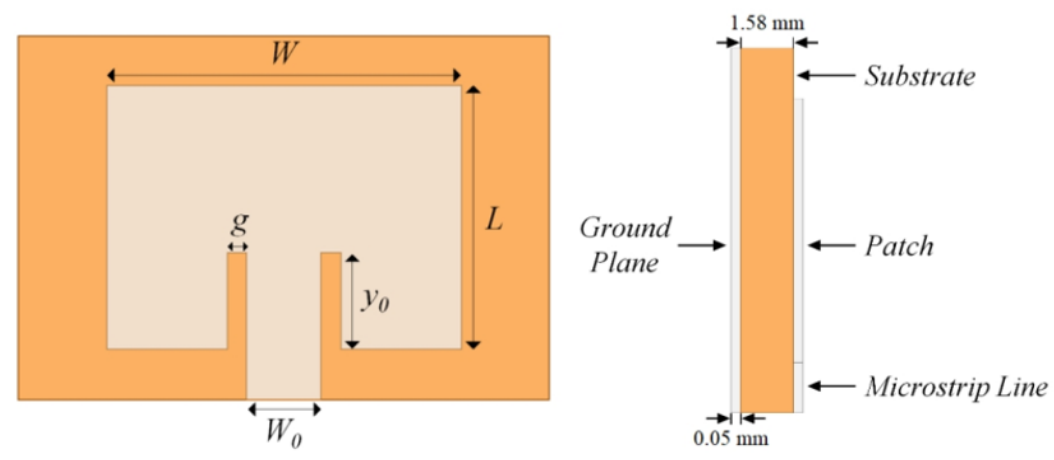

Fig. 1. Structure of the standard rectangular patch antenna. 
Fiberglass (FR4) was used as dielectric substrate, which has relative permittivity $\left(\varepsilon_{r}\right)$ of 4.4 , loss tangent $(\delta)$ of 0.02 and thickness $(h)$ of $1.58 \mathrm{~mm}$. Three settings of PBG structures quasi-periodic antennas printed in the substrate were used in this work. The first configuration consists of 101 air holes arranged in a 6-fold symmetry, as shown in Fig. 2 (a). The second one is formed by a mesh with 12-fold symmetry and 150 air holes were printed in the antenna substrate, as shown in Fig. 2 (b). The third one consists of 167 air holes distributed in a 6-fold modified symmetry, which is formed combining square and triangular elements [18], as shown in Fig. 2 (c).

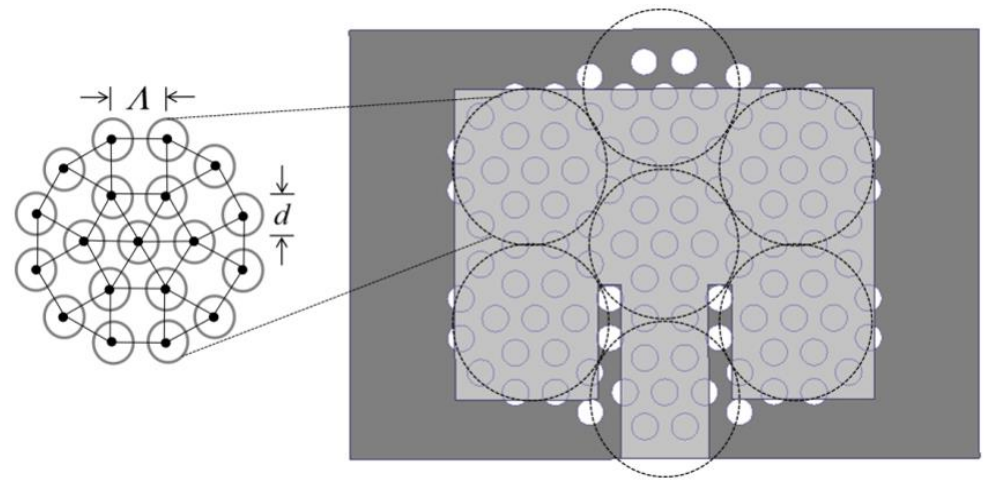

a)

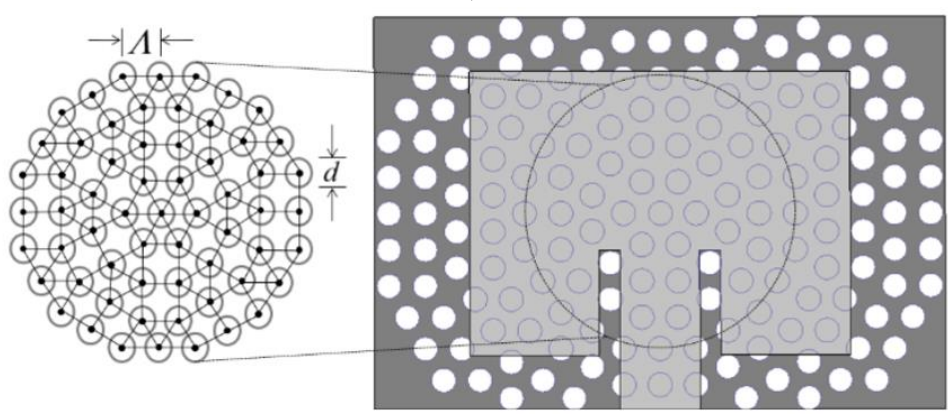

b)

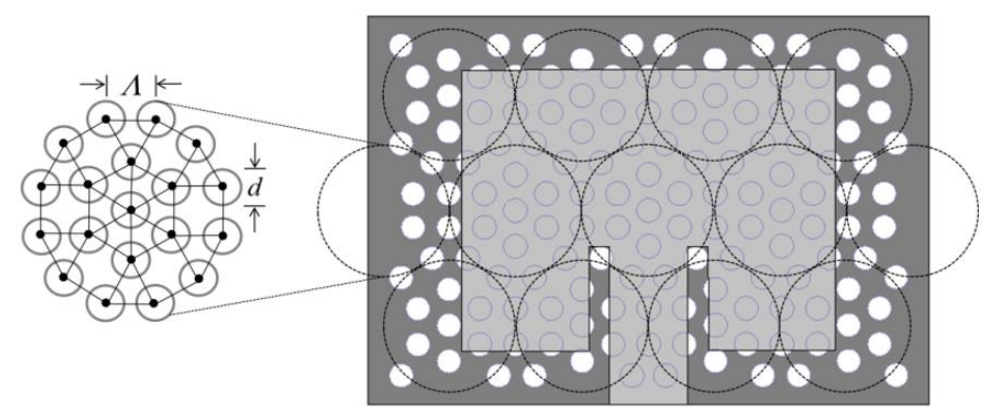

c)

Fig. 2. Quasi-periodic PBG antennas with (a) 6-fold symmetry, (b) 12-fold symmetry and (c) 6-fold modified symmetry.

For all settings, we have fixed the value of $1.0 \mathrm{~mm}$ for the diameter (d) of the air holes and $1.5 \mathrm{~mm}$ for the distance between the center of each one of them ( $\Lambda$ ).

\section{COMPUTATIONAL RESULTS}

Simulations were carried out to obtain the behaviour of the reference antenna and of the proposed settings of periodic PBG structures. The first analyze was conducted to study how each PBG structure affect the $S_{11}$ parameter in $\mathrm{dB}\left(\mathrm{S}_{11}\right)$ of the analyzed antennas and the results can be seen in Fig. 3 . 


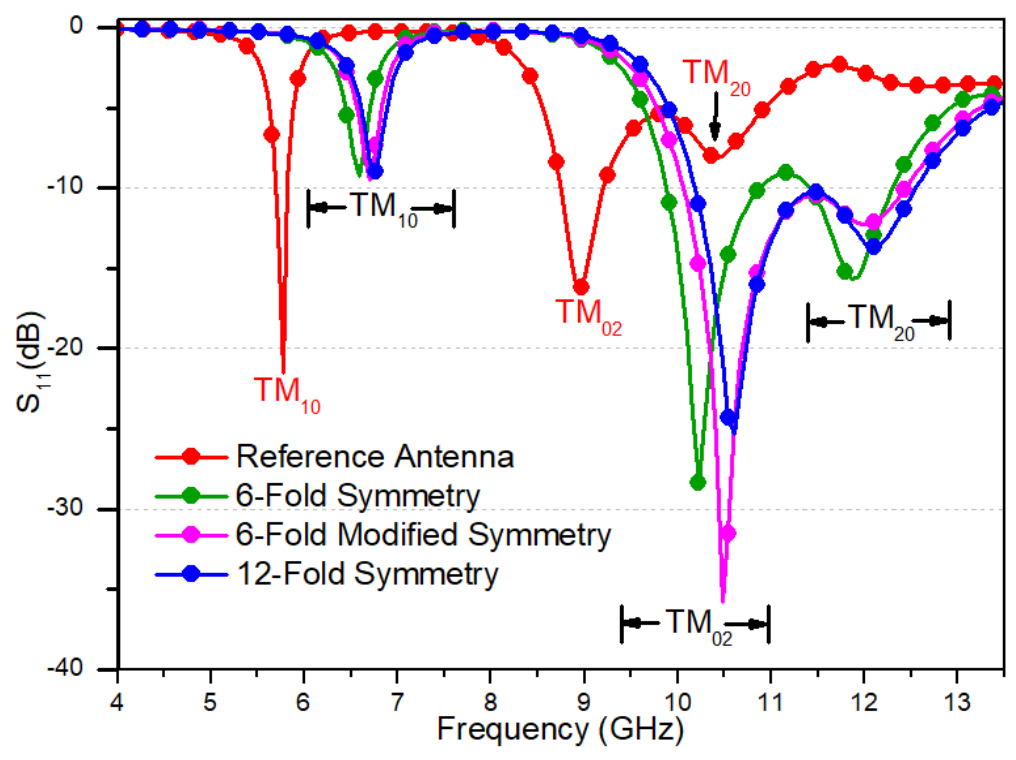

Fig. 3. $\mathrm{S}_{11}$ parameter in function of resonance frequency for all analysed antennas.

The results show that the antennas with quasi-periodic PBG structure shift the resonance frequency from $5.8 \mathrm{GHz}$ to $8.9 \mathrm{GHz}$ (6-fold symmetry), $10.6 \mathrm{GHz}$ (12-fold symmetry) and $10.5 \mathrm{GHz}$ (6-fold modified symmetry), considering the reduction of the dielectric constant. According to the study of propagation modes, performed for all antennas, it can be observed in Fig. 3 that the analyzed PBG structure cause a shift of the propagation modes to the right and no new mode was excited in the analyzed range. Thus, it can be seen a higher bandwidth than that one obtained for the reference antenna and lower $S_{11}$ value for the second operating band. In addition, it can be noted that the quasiperiodic PBG antenna with 6-fold modified symmetry showed better performance than the other antennas, once it provided higher bandwidth for the second operating band, approximately $22.5 \%$, and lower $\mathrm{S}_{11}$ value of $-35.8 \mathrm{~dB}$. All information mentioned previously are exposed in Table I, which presents the values of Resonance Frequency $\left(\mathrm{F}_{0}\right), \mathrm{S}_{11}$ parameter, Fractional Bandwidth (BW) and new dieletric constant. It is important to say that only the fractional bandwidth whose $S_{11}$ parameter values were below to $-10 \mathrm{~dB}$ were considered.

TAble I. Parameters of Simulations PResented in Fig.3

\begin{tabular}{ccccc}
\hline Antennas & $\mathbf{F}_{\mathbf{0}}(\mathbf{G H z})$ & $\mathbf{S}_{\mathbf{1 1}}(\mathbf{d B})$ & $\mathbf{B W}(\boldsymbol{\%})$ & $\begin{array}{c}\text { Dieletric } \\
\text { Constant }\end{array}$ \\
\hline Reference & $5.8 ; 8.9 ; 10.4$ & $-21,5 ;-16,3 ;-8.1$ & $2.8 ; 5.3 ;--$ & 4.4 \\
6-Fold & $6.6 ; 10.2 ; 11.9$ & $-9.2 ;-28.3 ;-15.6$ & $--; 9.8 ; 7.1$ & 3.18 \\
6-Fold Modified & $6.7 ; 10.5 ; 12.1$ & $-9.5 ;-35.8 ;-12.3$ & $--; 12.4 ; 8.1$ & 3.05 \\
12-Fold & $6.8 ; 10.6 ; 12.1$ & $-8.9 ;-25.3 ;-13.7$ & $--; 12,3 ; 8.8$ & 2.93 \\
\hline
\end{tabular}

If it is desired that the new structures have a resonant frequency at $5.8 \mathrm{GHz}$ as previously projected, the measures are recalculated and presented in Table II. 
Journal of Microwaves, Optoelectronics and Electromagnetic Applications, Vol. 19, No. 2, June 2020 DOI: http://dx.doi.org/10.1590/2179-10742020v19i2821

TABLE II. MEASUReS OF NEW StRuctures FOR $5.8 \mathrm{GHz}$

\begin{tabular}{cccc}
\hline Antennas & $\begin{array}{c}\text { Dieletric } \\
\text { Constant }\end{array}$ & W $(\mathbf{m m})$ & $\mathbf{L}(\mathbf{m m})$ \\
\hline Reference & 4.4 & 15.73 & 11.74 \\
6-Fold & 3.18 & 17.88 & 13.79 \\
6-Fold Modified & 3.05 & 18.16 & 14.08 \\
12-Fold & 2.93 & 18.44 & 14.36 \\
\hline
\end{tabular}

The study of the propagation modes is detailed in Figures 4, 5, 6 and 7, which show the electric field distribution in the substrate and the total gain for the three operating frequencies, considering each analysed antenna and their respective resonance modes, i. e., $\mathrm{TM}_{10}, \mathrm{TM}_{02}$ and $\mathrm{TM}_{20}$.
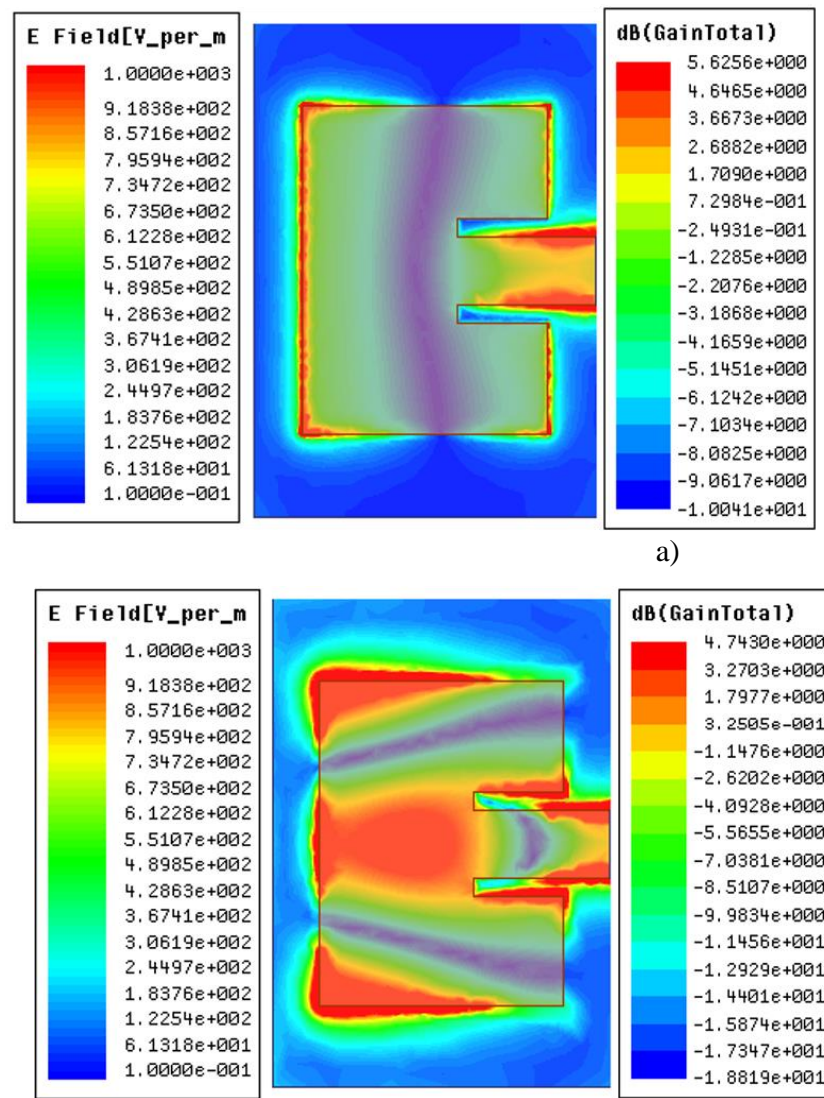

a)
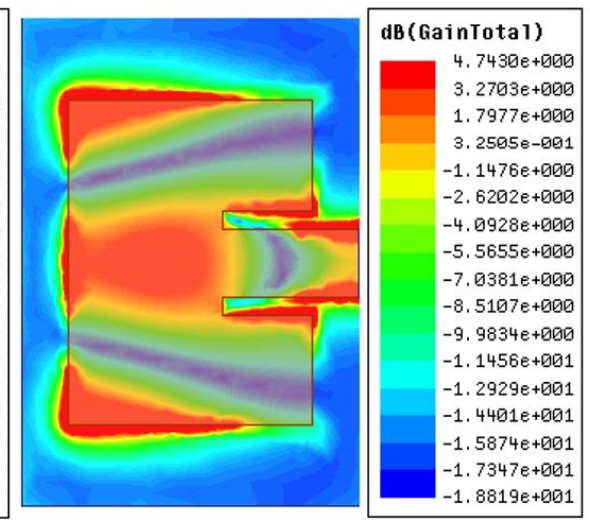

b)
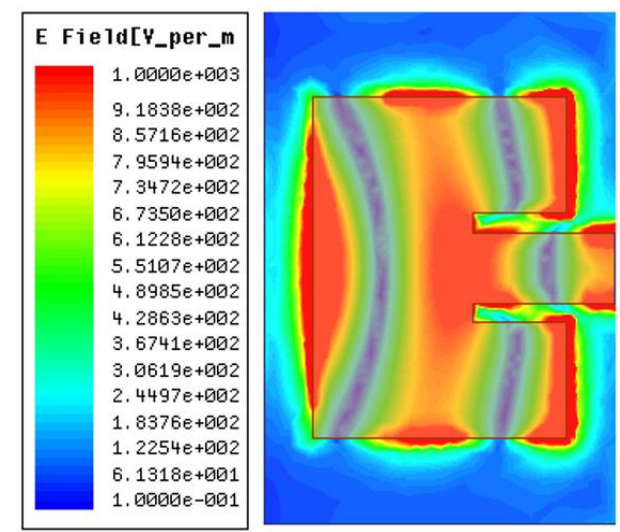

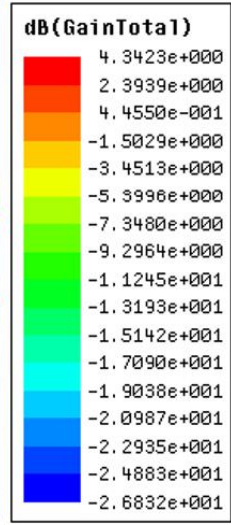

c)
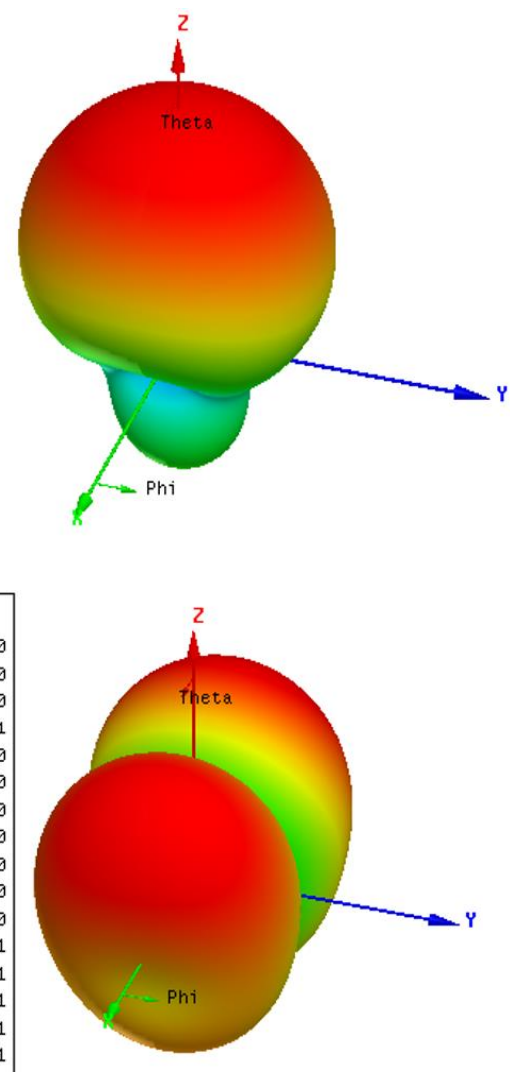

Fig. 4. Distribution of electric field and total gain for the reference antenna at (a) $5.8 \mathrm{GHz}\left(\mathrm{TM}_{10}\right)$, (b) $8.9 \mathrm{GHz}\left(\mathrm{TM}_{02}\right)$ and (c) $10.4 \mathrm{GHz}\left(\mathrm{TM}_{20}\right)$. 

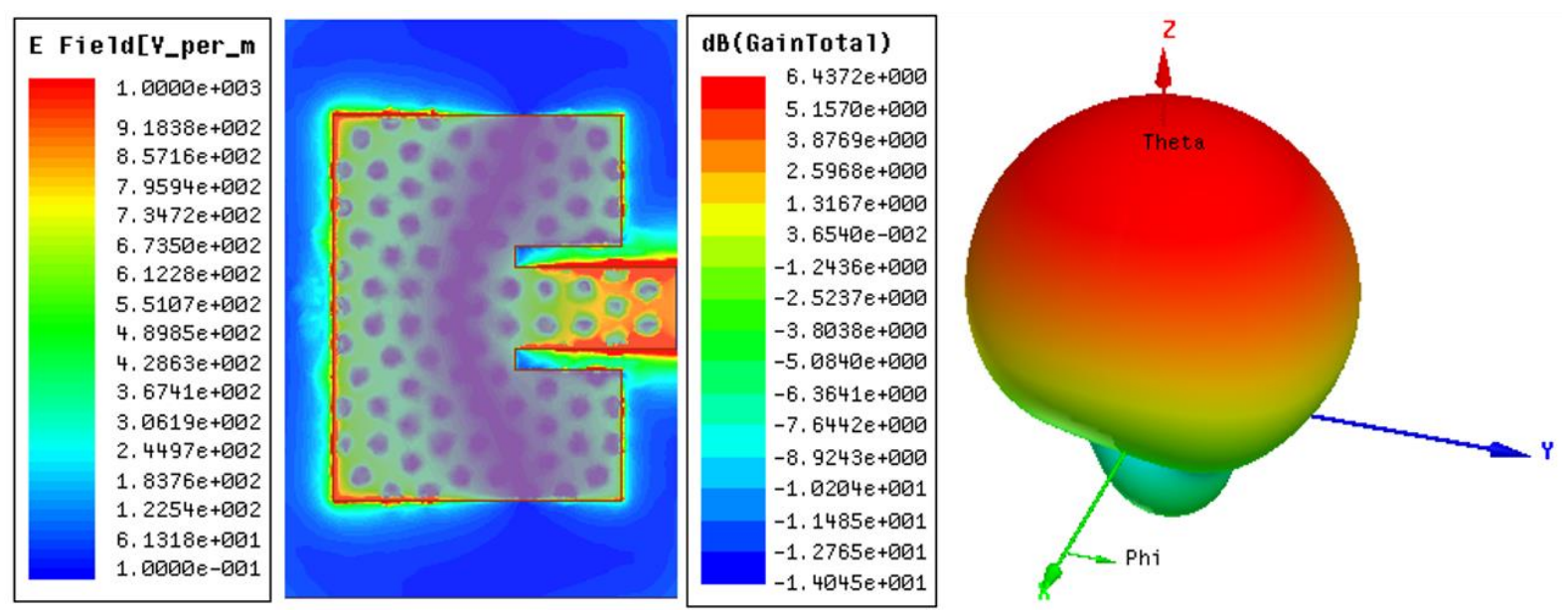

a)
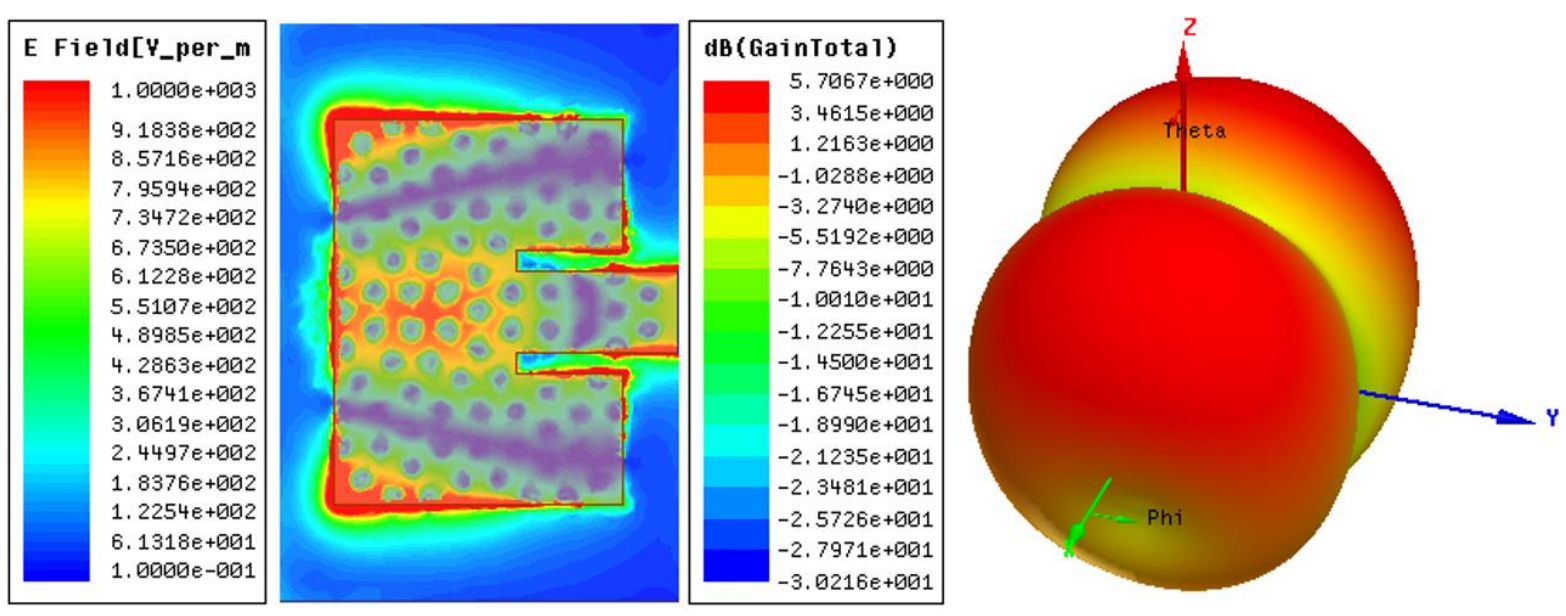

b)

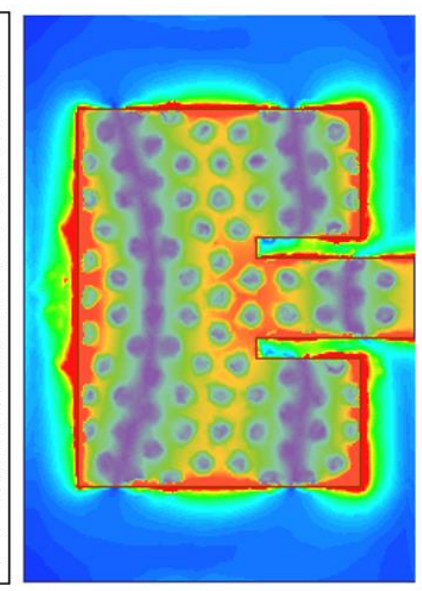

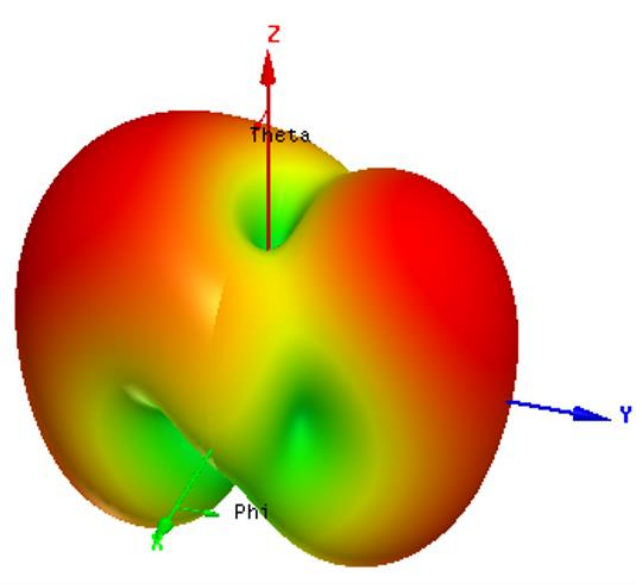

c)

Fig. 5. Distribution of electric field and total gain for the antenna with six-fold symmetry at (a) $6.6 \mathrm{GHz}$ (TM10), (b) 10.2 $\mathrm{GHz}\left(\mathrm{TM}_{02}\right)$ and (c) $11.9 \mathrm{GHz}\left(\mathrm{TM}_{20}\right)$. 

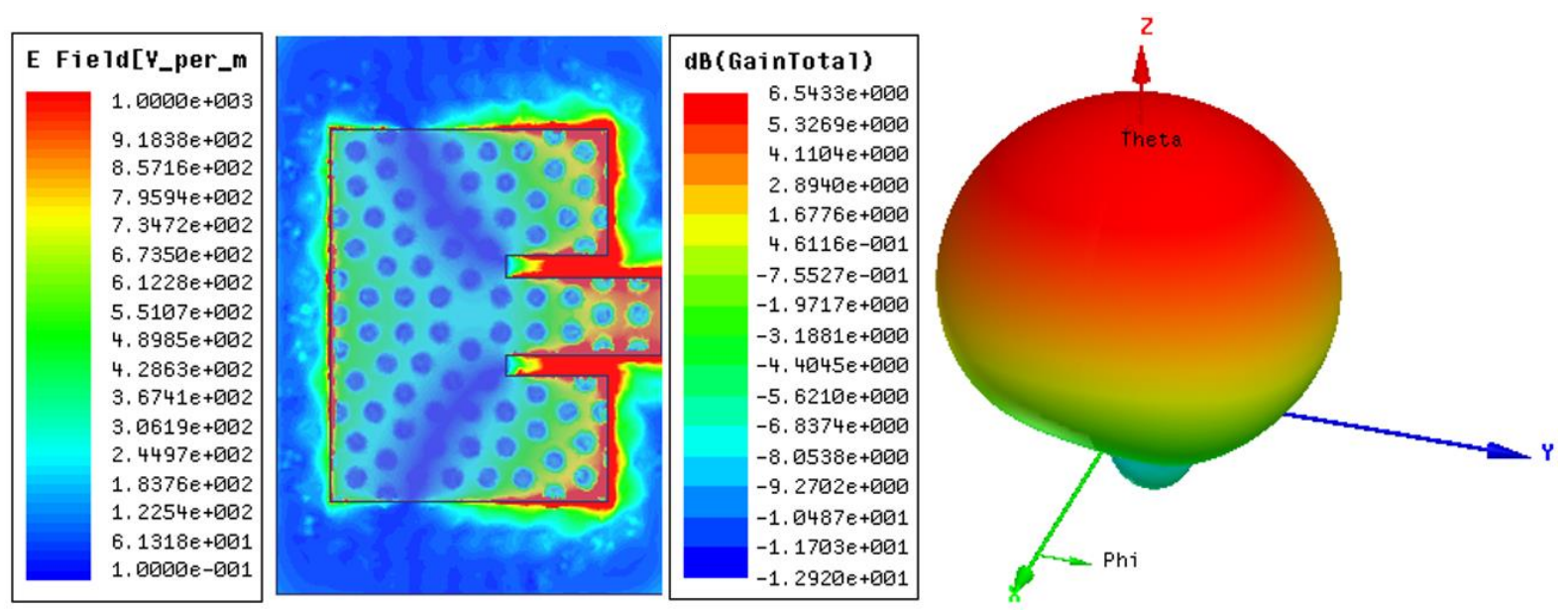

a)
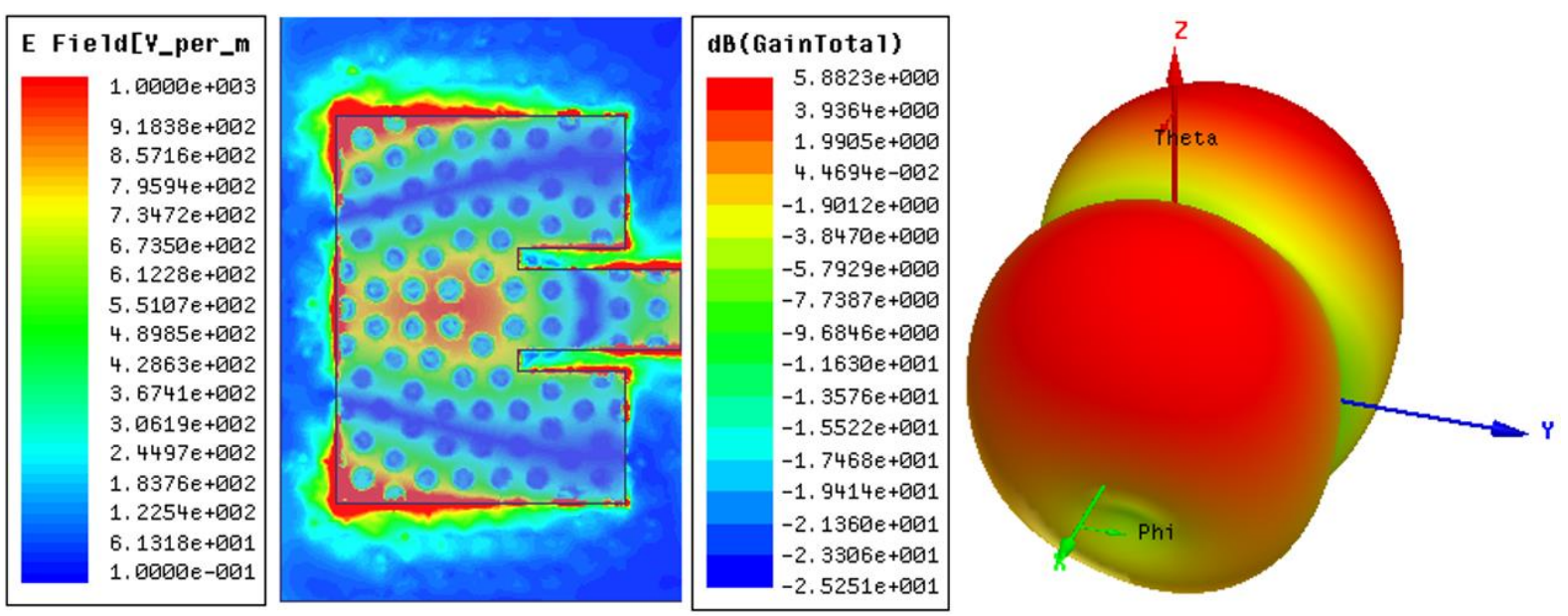

b)

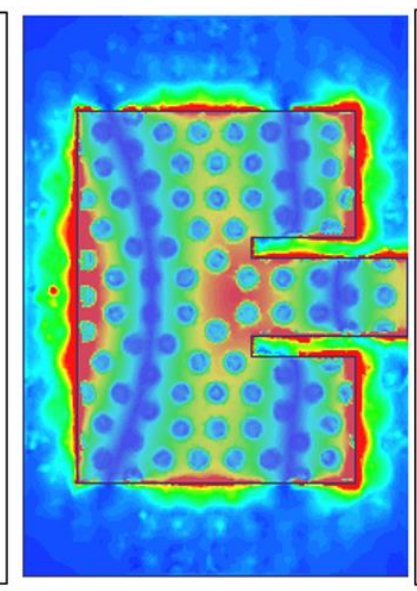

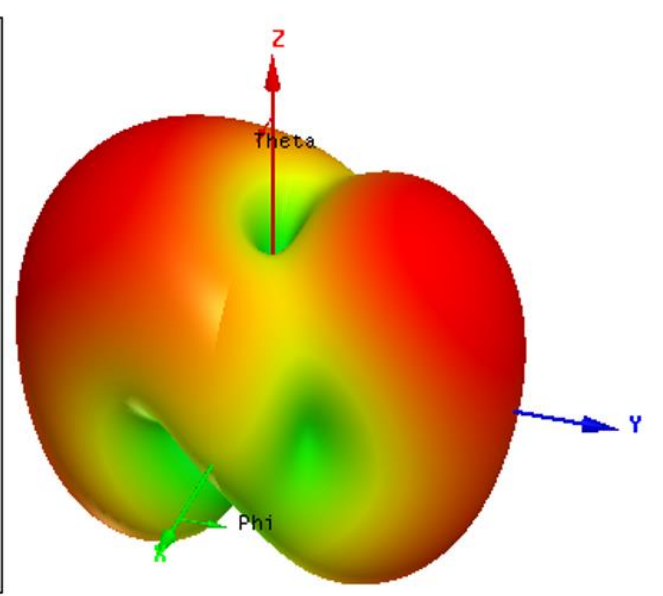

c)

Fig. 6. Distribution of electric field and total gain for the antenna with six-fold modified symmetry at (a) $6.7 \mathrm{GHz}\left(\mathrm{TM}_{10}\right)$, (b) $10.5 \mathrm{GHz}\left(\mathrm{TM}_{02}\right)$ and (c) $12.01 \mathrm{GHz}\left(\mathrm{TM}_{20}\right)$. 

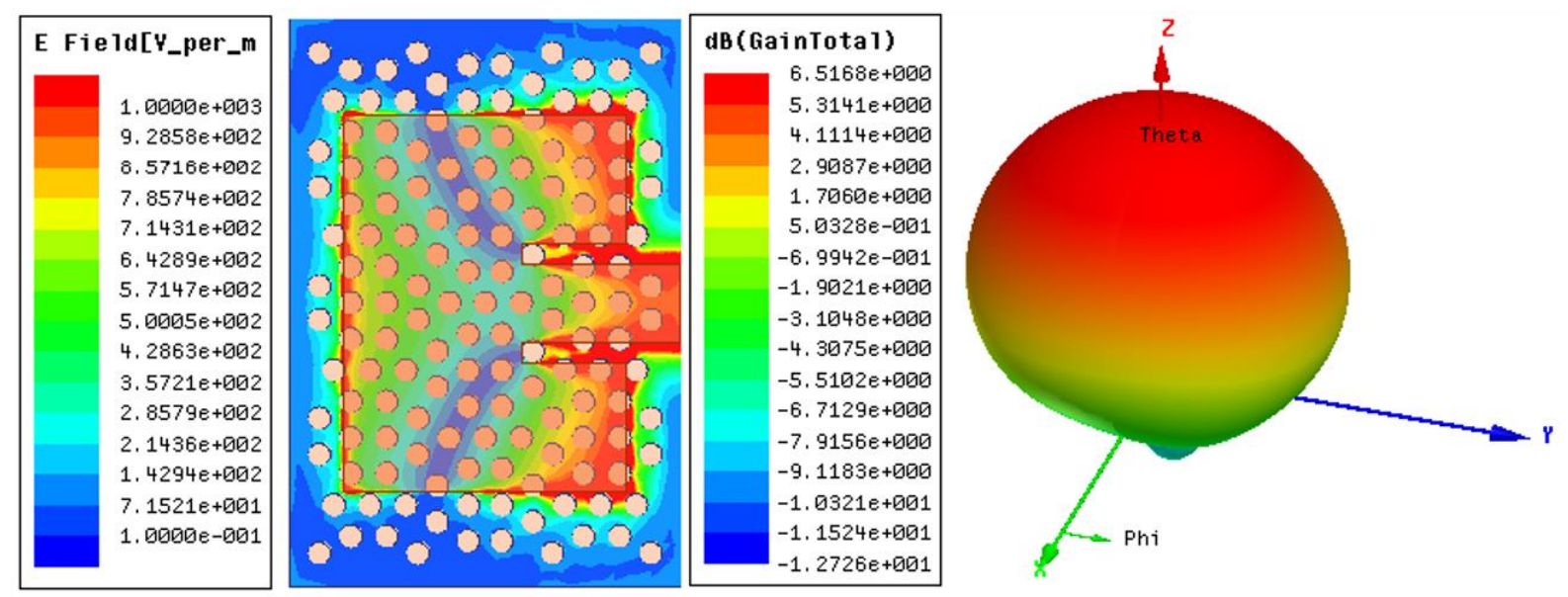

a)
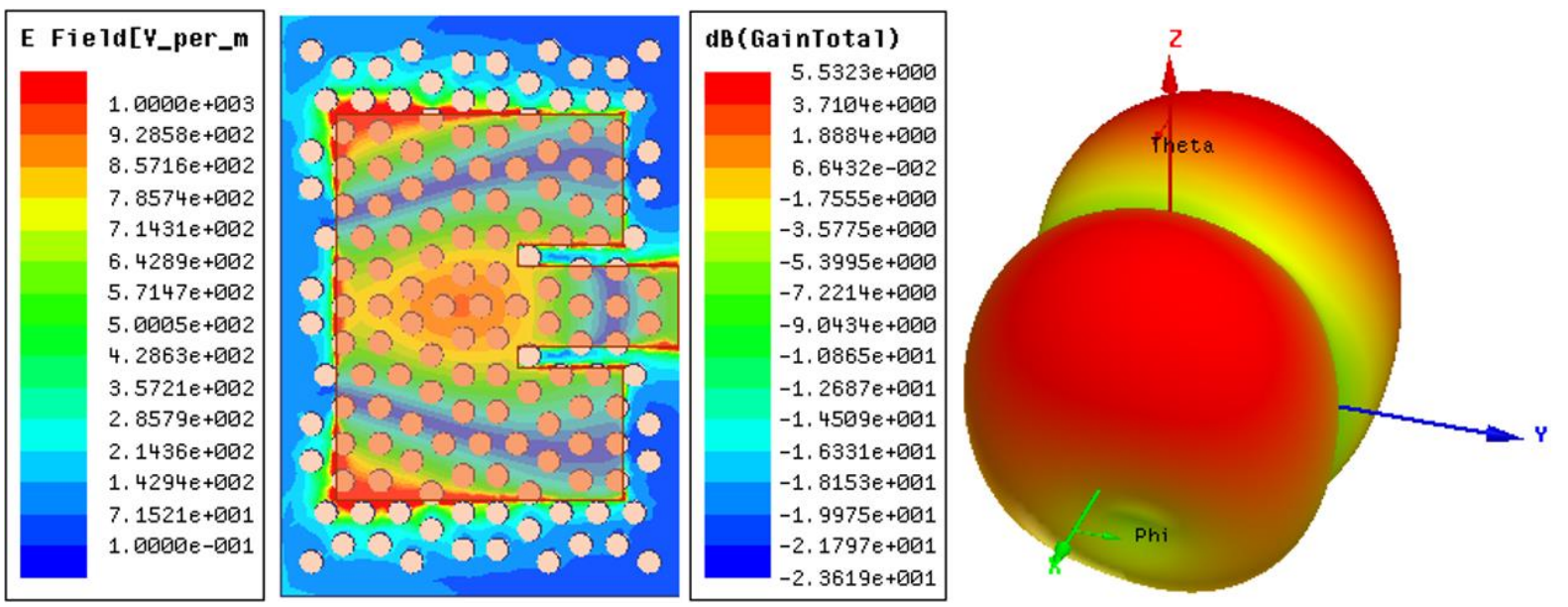

b)
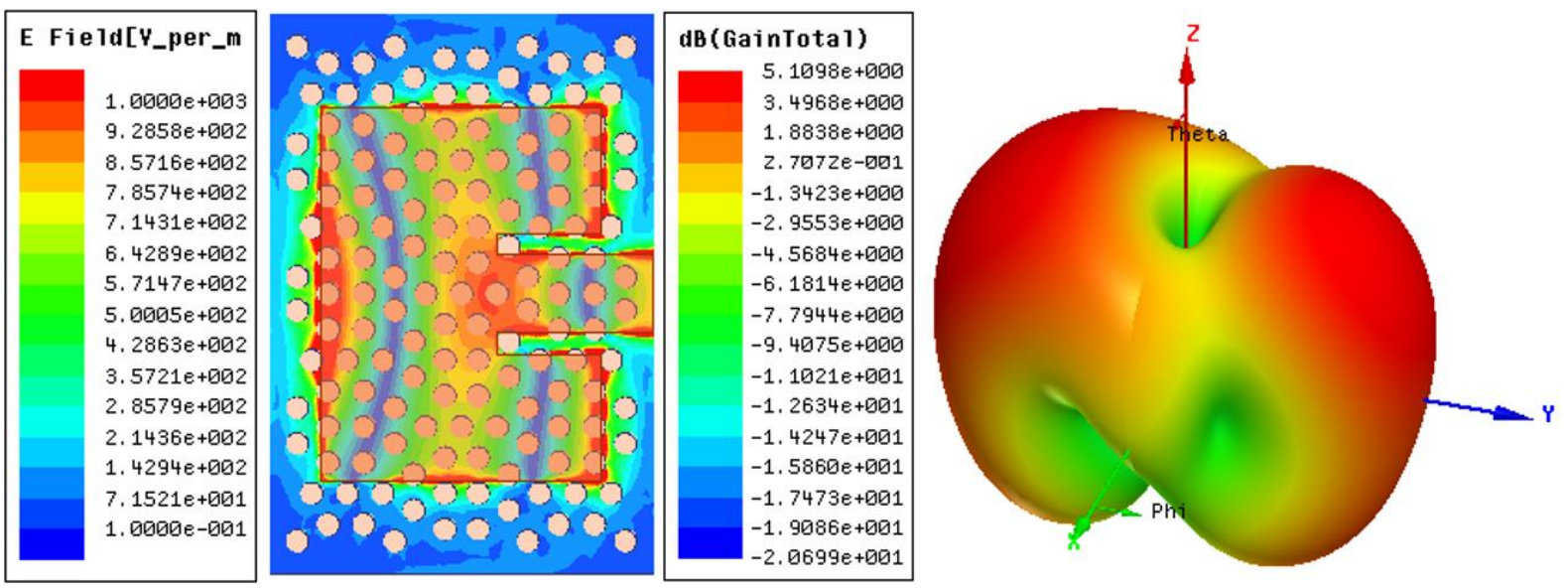

c)

Fig. 7. Distribution of electric field and total gain for the antenna with twelve-fold symmetry at (a) $6.8 \mathrm{GHz}$ (TM10), (b) 10.6 $\mathrm{GHz}\left(\mathrm{TM}_{02}\right)$ and (c) $12.1 \mathrm{GHz}\left(\mathrm{TM}_{20}\right)$. 
As shown in Figs. 4, 5, 6 and 7, the $\mathrm{TM}_{10}, \mathrm{TM}_{02}$ and $\mathrm{TM}_{20}$ modes can be visualized in the distribution of the electric field in the substrate of the antennas. It can be seen a higher concentration of electric field at the edges of the transmission line and around the inset-fed for the reference antenna in Fig. 4. Thus, it is possible to affirm that the antennas with quasi-periodic holes in the substrate presented a more uniform distribution of electric field along the patch than the reference antenna. In addition, the total gain for all configurations of the proposed PBG antennas was bigger than the antenna without PBG.

\section{PRACTICAL RESULTS}

Fig. 8 shows some prototypes that were built and measured for the reference and proposed PBG antennas. The data obtained from the measurements of the built antennas were compared to those obtained from computational simulation, which were reported previously. Fig. 8 shows, from the left to the right, the prototypes for the reference antenna and quasi-periodic PBG antennas with 6,12 , and 6-fold modified symmetries, respectively. These antennas were built by using a prototype machine, model LPKF ProtoMat S42, which provided a very precise physical models regarding to simulated structures.

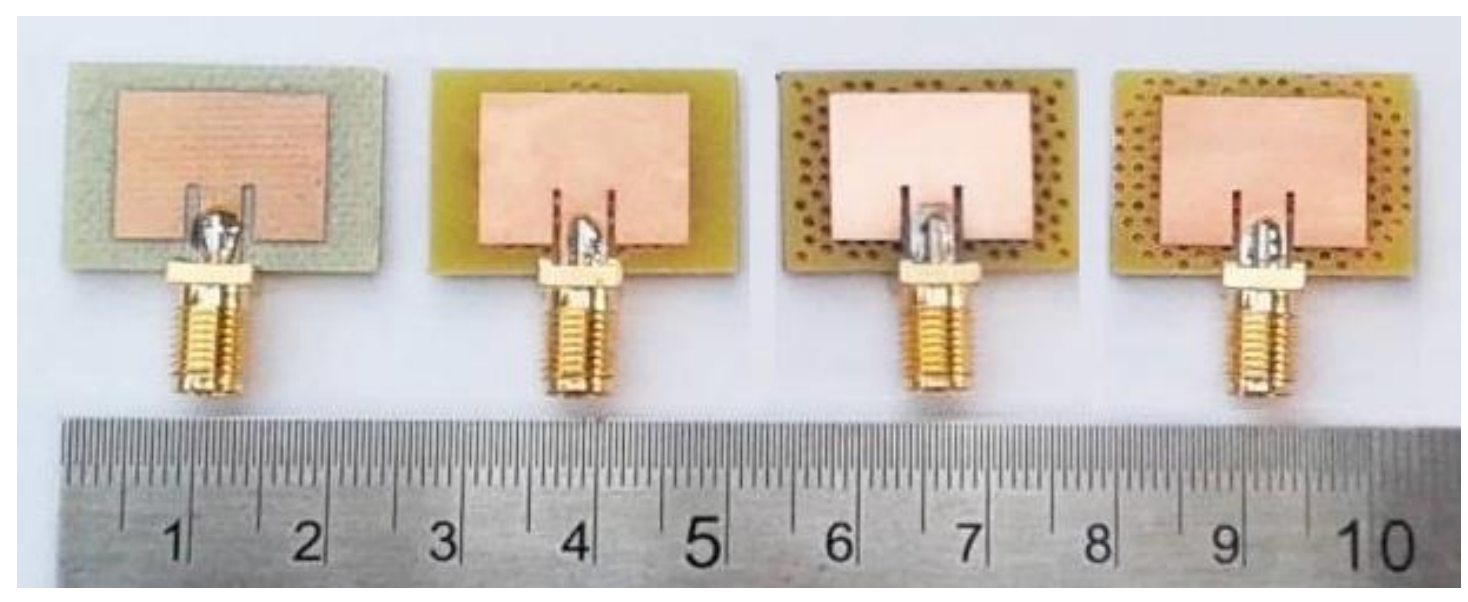

Fig. 8. Prototypes of the analyzed antennas.

Fig. 9 shows the comparison between the simulated and measured values for the configuration with 6-fold symmetry. It can be verified that the measurement of the proposed antenna provided better results than those obtained by simulations, presenting lower $S_{11}$ value for the first and second operating band. Thus, it can be seen a good agreement between simulated and measured values.

The comparison between simulated and measured values for the configuration with 12-fold symmetry is showed in Fig. 10. It can be noted a good agreement between the simulated and measured values with a small displacement for the first operating band and a lower $S_{11}$ value, considering the measured values for the first and second operating band. 


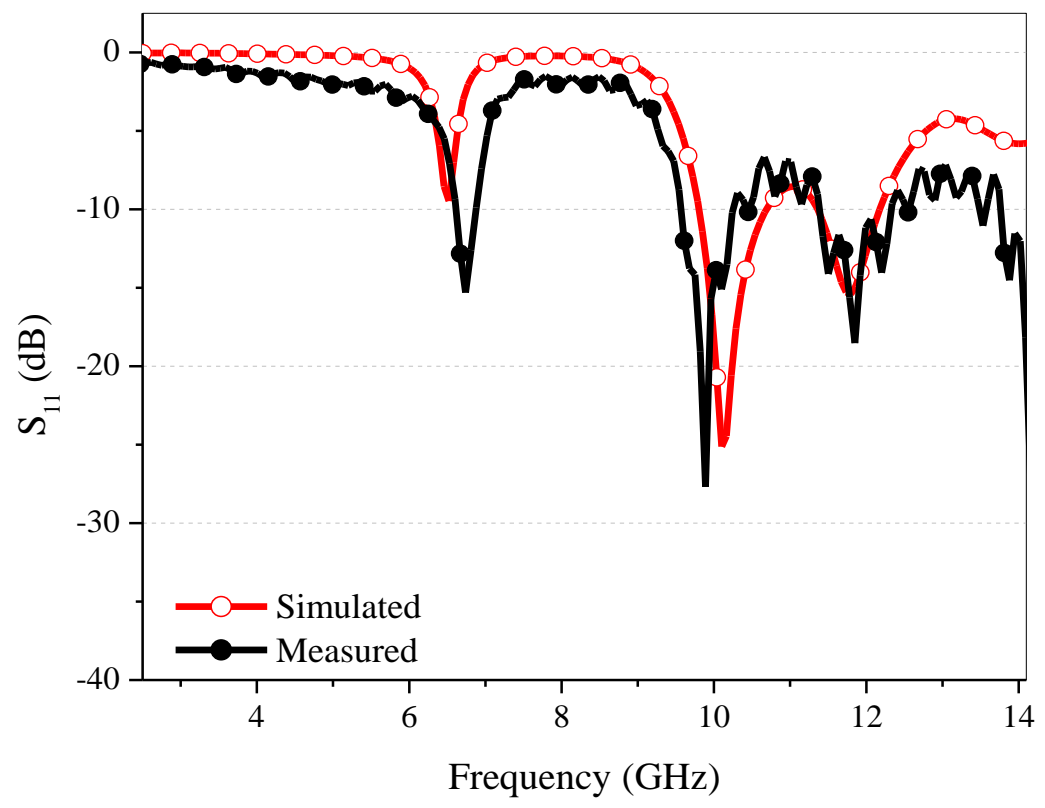

Fig. 9. $\mathrm{S}_{11}$ parameter in function of resonance for the quasi-periodic PBG antenna with 6-fold symmetry.

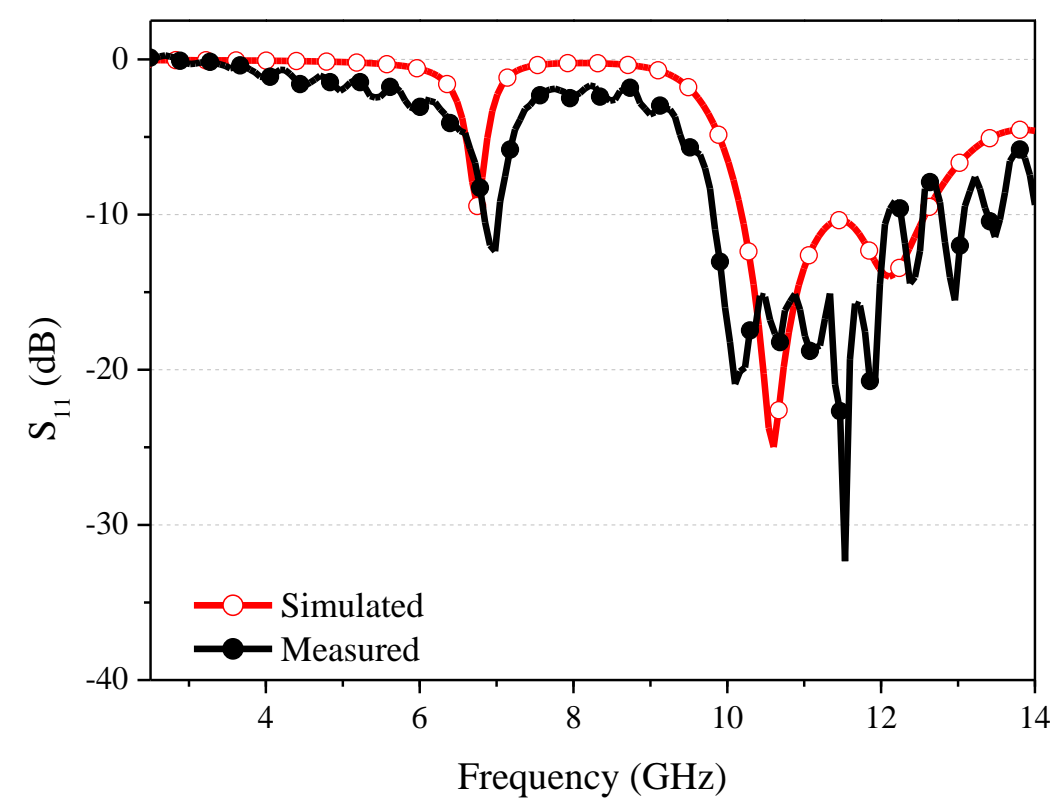

Fig. 10. $\mathrm{S}_{11}$ parameter in function of resonance frequency for quasi-periodic PBG antenna with 12-fold symmetry.

Fig. 11 shows the comparison between the simulated and measured values for the configuration with 6-fold modified symmetry. From these results, it can be seen a good agreement between the simulated and measured values. In addition, it is important to say that the constructed antenna has better performance than what was simulated, once it had higher bandwidth for the second operating band and $S_{11}$ value for the first operating band. 


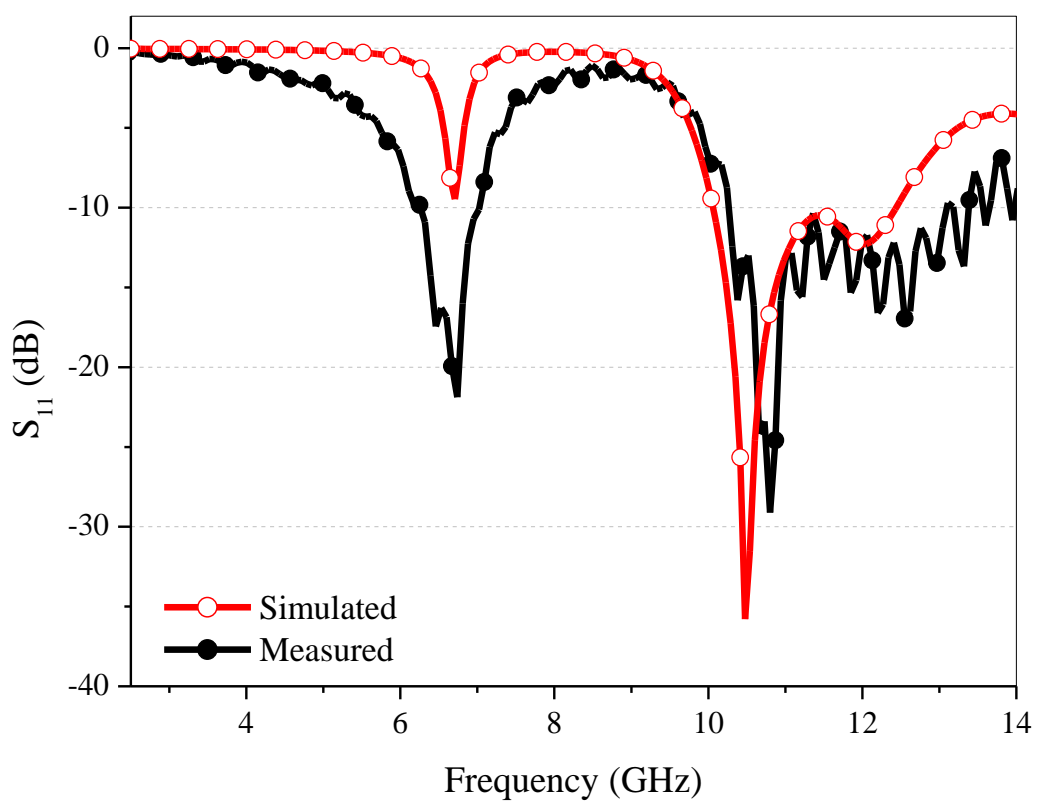

Fig. 11. $\mathrm{S}_{11}$ parameter in function of resonance frequency for quasi-periodic PBG antenna with 6-fold modified symmetry.

Therefore, it can be affirm that the validation of simulated results from experimental measurements was successfully performed. Considering some small variations, observed due to the noise in the measurements, it can be see a good agreement between measured and simulated values for all manufactured antennas.

\section{CONCLUSIONS}

In this paper, a rectangular microstrip antenna was designed to operate at $5.8 \mathrm{GHz}$ and its performance were analysed considering some model of quasi-periodic PBG structure. The analysed antennas consisted of rectangular microstrip antennas whose substrates were modified by inserting in it arranges of air holes in a quasi-periodic PBG structures with 6, 12 and 6-fold modified symmetries. In this study, the values for the diameter $(1.0 \mathrm{~mm})$ of the air holes and for distance between the center of them $(1.5 \mathrm{~mm})$ were kept fixed for all configurations. Therefore, all differences in the performance of them come from the arrangement of the air hole, once the physical dimensions of all them are also the same.

The proposed antennas were compared to a reference antenna (without PBG) in term of $S_{11}$ parameter value, bandwidth, electric field distribution in the substrate and total gain. The quasiperiodic PBG antennas showed a significant increasing in the bandwidth, total gain and reduction of the $S_{11}$ parameter for the second operating band regarding to the reference antenna. Besides, an important study of propagation modes was also realized for all antennas, from which we can conclude that the analyzed PBG structure can cause a shift of the propagation modes to right without exciting new modes at least in the analyzed range, having only their resonant frequencies shifted. Also, the results point at the possibility of suppressing or at least attenuated undesired resonance modes, as showed in Fig. 3. 
The computational results were compared to those obtain from the measurements of some prototypes, which presented good agreement with computational results. According to the analysis, it can be conclude that the quasi-periodic PBG antenna with 6-fold modified symmetry showed the best performance for the simulated and measured data. Thus, this paper shows that it is possible to construct prototype of microstrip antennas with quasi-periodic PBG substrates with very satisfactory performance for applications that require thicker bandwidth. Also, it was observed a displacement in the desired operating frequency, which varied according to the used symmetry. That comes from the fact the insertions of air hole in the substrate reduced the effective dielectric constant of the antennas substrate, implying in the reduction of its resonance frequency, as observed.

Thus, for future work, we have intended to analyse the behaviour of periodic [23] and quasi-periodic by using an Artificial Neural Network, which operates as a non-linear interpolation to adjust the main parameters of the microstrip antennas with PBG structure in the substrate in order to find the design frequency of the antenna, required to obtain the optimal operating frequency.

\section{ACKNOWLEDGMENT}

The authors would like to thank UFRN by structural support, UFERSA/PPGSCA by the commercial software license $\left(n^{\circ}\right.$ 1058710) and GTEMA-IFPB, IFRN for the technical support and CAPES.

\section{REFERENCES}

[1] J. P. P. Pereira, "Estruturas PBG Periódicas e Quase Periódicas para Antenas de Microfita com Aplicação em Veículos Aéreos não Tripulados," M.S. thesis, Dept. Elect. Eng., UFRN Univ., Natal, Brazil, 2016.

[2] P. N. Tan, Y. K. Chan, T. S. Lim and G. Vetharatnam, "Design and Development of a Sidelooking Microstrip Patch Antenna for Unmanned Aerial Vehicle Synthetic Aperture Antenna," in Proc. Electromagnetics Research Symposium Proceedings. Taipei, Taiwan, 2013, pp. 991-993.

[3] J. P. P. Pereira, J. P. da Silva and H. D. de Andrade, "A New Design and Analysis of a Hexagonal PBG Microstrip Antenna,” Microwave and Optical Technology Letters, vol. 57, pp. 2147-2151, Jun. 2015.

[4] C. A. Balanis, Antenna theory: Analisys and design. John Wiley \& Sons, Hoboken, Nova Jersey, USA: 2005

[5] S. Bhavsar and B. Singh, "Electromagnetic Band Gap Structures Incorporated in Antenna Array: A Review," Int. Jour. Comp. Tech. Elec. Eng. (IJCTEE), vol. 3, pp. 22-28, Apr. 2013.

[6] S. Pflaum et al., "Exploitation of the UC-PBG Structure as Ground Plane to Enhance Microstrip Antenna Bandwidth," in Proc. Antennas and Propagation Society International Symposium (APSURSI), IEEE, 2014, pp. 442-443.

[7] G. M. Zelinski, G. A. Thiele and M. L. Hastriter, "Half width leaky wave antenna," IET Microwaves, Antennas and Propagation, vol. 1, no. 2, pp. 341-348, Apr. 2007.

[8] M. Bozzi, A. Georgiadis and K. Wu, "Review of Substrate-Integrated Waveguide Circuits and Antennas," IET Microwaves, Antennas and Propagation, vol. 5, no. 8, pp. 909-920, Jun. 2011.

[9] J. F. Almeida and C. L. S. S. Sobrinho, "Influência do Posicionamento de uma Estrutura PBG sobre a Largura de Banda de uma Antena de Microfita," IEEE Latin America Transactions, vol. 2, no. 1, pp. 25-30, Mar. 2004.

[10] H. D. de Andrade, "Desenvolvimento de um Ressoador Retangular de Fenda com Múltiplas Camadas de Substrato e com Utilização de Material PBG para Sistemas de Comunicação sem Fio,” M.S. thesis, Dept. Elect. Eng., UFRN Univ., Natal, Brazil, 2013.

[11] Md. S. Alam et al., "Development of Electromagnetic Band Gap Structures in the Perspective of Microstip Antenna Design," International Journal of Antennas and Propagation, vol. 2013, pp. 1-22, Mar. 2013.

[12] M. S. Alam, M. T. Islam and N. Misran, "Design analysis of an electromagnetic bandgap microstrip antenna," The American Journal of Applied Sciences, vol. 8, no. 12, pp. 1374-1377, 2011.

[13] F. Yang and Y. Rahmat-Samii, "Applications of electromagnetic band-gap (EBG) structures in microwave antenna designs," in Proceedings of the 3rd International Conference on Microwave and Millimeter Wave Technology (ICMMT 2002), IEEE, 2002. pp. 528-531.

[14] D. Qu and L. Shafai, "Wideband microstrip patch antenna with EBG substrates," in Proc. IEEE Antennas and Propagation Society International Symposium, IEEE, 2005, pp. 594-597.

[15] S. G. Johnson and J. D. Joannopoulos, "Introduction to Photonic Crystals: Bloch's Theorem, Band Diagrams and Gaps (but no Defects)," MIT, 2003, pp. 1-16. [Online]. Available: http://ab-initio.mit.edu/photons/tutorial/photonic-intro.pdf. 
DOI: http://dx.doi.org/10.1590/2179-10742020v19i2821

[16] C. S. J. Arismar, "Recent progress and novel applications of photonic crystal fibers," Report on Progress in Physics, vol. 73, no. 2, pp. 024401, Jan. 2010. [Online]. Available: https://iopscience.iop.org/article/10.1088/00344885/73/2/024401/meta.

[17] S. Kim and C. Kee E. P. Wigner, "Dispersion Properties of Dual-Core Photonic Quasicrystal Fibers," Optics Express, vol. 15, pp. 15885-15890, Aug. 2009.

[18] R. Bhattacharjee, K. Senthilnathan and S. Sivabalan, "Exploring a Photonic Quasi-Crystal Fiber for Enhacing the Efficiency of Second Harmonic Generation: Modeling and Analysis," Optical Materials, vol. 35, no. 12, pp. 21322137, Oct. 2013.

[19] J. P. Silva and M. F. Bellaguarda, "Coupling Characteristics of Multicore Photonic Crystal Fiber Doped with Germanium," in 2011 SBMO/IEEE MTT-S International Microwave and Optoelectronics Conference (IMOC 2011). IEEE, 2011. pp. 102-105.

[20] A. O. Guimarães, J. P. Silva and E. R. M. Dantas, "Chromatic Dispersion of an Optical Fiber Based on Photonic Quasicrystals with Twelve Fold Symmetry and its Application as Directional Coupling," Journal of Microwaves, Optoelectronics and Electromagnetic Applications, vol. 14, no. 2, pp. 170-183, Dec. 2015.

[21] J. P. P. Pereira, J. P. Silva and A. O. Guimarães, "Microstrip Antennas Design Based In Periodic and Quasiperiodic PBG Symmetries," Journal of Microwave and Optical Technology Letters, vol. 57, no. 12, pp. 2914-2917, Sep. 2015.

[22] A. O. Guimarães, J. P. Silva and J. P. P. Pereira, "Analysis of a Microstrip Antenna with Variation on Substrate PBG Hexagonal," Journal of Microwave and Optical Technology Letters, vol. 58, no. 4, pp. 826-831, Feb. 2016.

[23] A. O. Guimarães, J. P. Silva and J. P. P. Pereira, "Projeto de Antenas de Microfita com Substrato PBG Otimizado por Redes Neurais Artificiais," in Proc. MOMAG, Porto Alegre, RS, Brazil, 2016. 